\title{
Hepatocyte Apoptosis at the Interplay of Intracellular Organelles and Membrane-Bound Receptors: Targets for Therapy
}

\section{Golnar Karimian*, Klaas Nico Faber and Han Moshage}

Department of Gastroenterology and Hepatology, University Medical Center Groningen, University of Groningen, Groningen, The Netherlands

\begin{abstract}
Hepatocyte apoptosis is ubiquitous in liver diseases. Although apoptosis is primarily a non-inflammatory process responsible for removing excess or damaged cells, un-controlled apoptosis can deteriorate organ function. E.g. if apoptotic bodies are not eliminated, their membranes become permeable, leading to the release of cellular fragments into the extracellular space and triggering an inflammatory response, a process called secondary necrosis. In massive liver injury, the ability of phagocytes to identify and clear apoptotic bodies is likely disturbed and an inflammatory response is observed despite an initial apoptotic stimulus in the liver. Therefore, understanding the cellular processes and molecular signaling pathways regulating apoptosis and/or necrosis in hepatocytes is essential to the development of new therapeutic strategies for (chronic) liver diseases. In particular, the intracellular organelles and membrane receptors that are involved in hepatocyte cell death and their interactions are of substantial interest, as a single toxic stimulus often activates several intracellular apoptotic pathways simultaneously. In this review, we discuss recent advances in organelle-mediated and membrane receptor-mediated cell death and potential targets for therapy in hepatocytes.
\end{abstract}

Keywords: Hepatocyte; Apoptosis; Receptors

\section{Introduction}

Liver diseases belong to the top 10 of leading diseases for humans. In clinical practice, liver injury is divided into acute and chronic diseases, based on the duration or persistence of liver injury. After recovery from acute liver injuries, normal liver function and architecture are restored. In contrast, liver functions in most chronic liver injuries are abnormal and persistent changes in liver architecture occur. Hepatocytes comprise $80 \%$ of all liver cells and hepatocyte injury is often central in the pathogenesis of liver diseases [1]. Prolonged hepatocyte injury results in an excessive wound healing response, leading to hepatic inflammation and fibrogenesis. Liver fibrosis is the hallmark of chronic liver diseases that may progress to end-stage liver disease and hepatocellular carcinoma. Toxic bile salts, cytokines, reactive oxygen species, free fatty acids and drugs induce hepatocyte injury.

Hepatocyte injury can result in hepatocyte cell death via apoptosis and/or necrosis [2,3]. Necrosis is a passive process that associates with metabolic disruption, energy depletion (loss of ATP), mitochondrial swelling and rupture of the plasma membrane. Subsequently, the release of cellular content into the extracellular environment and systemic circulation triggers an inflammatory response in the liver. Apoptosis is an ATP-dependent process also known as programmed cell death. Apoptosis is characterized by DNA condensation, nuclear fragmentation, plasma membrane blebbing, cell shrinkage and the formation of apoptotic bodies. In the liver, surrounding phagocytosing cells clear apoptotic bodies and limit the inflammatory response [2-5].

Although apoptosis is primarily a non-inflammatory process responsible for removing excess or damaged cells, un-controlled apoptosis (as in pathologic conditions) can deteriorate organ function [6]. Hepatocyte apoptosis is ubiquitous in liver diseases [1,7-11]. In the liver, apoptosis contributes to inflammation by promoting the activation of Kupffer cells and myofibroblasts. Following the uptake of apoptotic bodies, Kupffer cells express death ligands such as TNFa, TRAIL and FasL [12]. All these death ligands may induce apoptosis in hepatocytes via death-receptor induced signaling cascades and thus aggravate liver injury $[3,13,14]$. In addition, activated myofibroblast (derived from portal fibroblasts and HSCs $[15,16]$ ) are able to engulf apoptotic bodies and subsequently produce profibrogenic factors such as TGF $\beta$ and type I collagen $[17,18]$. These data link hepatocyte apoptosis to liver inflammation and liver fibrosis in chronic liver diseases and suggest that the most direct therapeutic strategy for repressing liver damage is to eliminate the cause of hepatocyte injury. For example, many chronic hepatitis B patients with end-stage liver disease had significant recovery and reversal of liver fibrosis with antiviral therapy and no longer required urgent transplantation (reviewed by [19]). Therefore, removing the cause for hepatocyte injury has become a potential therapeutic strategy for advanced liver diseases. However, effective treatments do not exist for many liver diseases such as primary sclerosing cholangitis, NASH, ASH and patients with chronic HCV or HBV unresponsive to antiviral therapies. For such patients anti-apoptotic strategies, reducing hepatocyte cell deathmediated inflammation and fibrogenesis, are beneficial [20-22]. Thus, understanding the cellular processes and molecular signaling pathways mediating hepatocyte apoptosis is essential to the development of new therapeutic strategies. In particular, the intracellular organelles and membrane receptors that are involved in hepatocyte cell death and their interactions are of substantial interest, as a single toxic stimulus often activates several intracellular apoptotic pathways simultaneously. In this review, we discuss recent advances in organelle- and membrane receptor-mediated cell death and potential targets for therapy in hepatocytes.

*Corresponding author: Golnar Karimian, Section Hepatobiliary Surgery and Liver Transplantation, Surgical Research Laboratory, Department of Surgery, University Medical Center Goningen, UMCG, Hanzeplein 1,9713 GZ Groningen, The Netherlands, Tel: 31-50-3611976; Fax: 31-50-3632796; E-mail: g.karimian01@umcg.nl

Received December 07, 2012; Accepted December 28, 2012; Published December 31, 2012

Citation: Karimian G, Faber KN, Moshage H (2013) Hepatocyte Apoptosis at the Interplay of Intracellular Organelles and Membrane-Bound Receptors: Targets for Therapy. Clin Exp Pharmacol S3:002. doi:10.4172/2161-1459.S3-002

Copyright: (c 2013 Karimian G, et al. This is an open-access article distributed under the terms of the Creative Commons Attribution License, which permits unrestricted use, distribution, and reproduction in any medium, provided the original author and source are credited. 


\section{Organelle-mediated cell death}

Mitochondria: Mitochondrial dysfunction is a common observation in several acute and chronic liver diseases such as ASH, NAFLD, drug-induced hepatotoxicity, viral hepatitis, biliary cirrhosis, hepatocellular carcinoma, ischemia/reperfusion injury and transplant rejection [23]. Mitochondria play an essential role in regulating the intrinsic pathway of hepatocyte apoptosis as well as hepatocyte necrosis [3,24-28]. Mitochondrial Permeability Transition (MPT) is a key mechanism underlying both apoptosis and necrosis (Figure 1). MPT is characterized by an increase in the permeability of the inner mitochondrial membrane, resulting in the loss of membrane potential, mitochondrial swelling and the rupture of the outer mitochondrial membrane [26]. Opening of the Permeability Transition Pore (mPTP) in the mitochondrial inner membrane is suggested to initiate the MPT. In addition, outer membrane channels such as Mitochondrial Apoptosis-Induced Channel (MAC) and the Voltage Dependent Anion Channel (VDAC), directly or indirectly, are involved in mitochondrial permeabilization during apoptosis and/or necrosis (Figure 1) [29]. Mitochondrial Outer Membrane Permeabilization (MOMP) during intrinsic apoptosis leads to the release of apoptotic factors such as cytochrome c, Second Mitochondrial Activator of Caspase/Direct IAP Binding protein with Low pI (SMAC/DIABLO), High-Temperature Requirement protein A2 (HtrA2/Omi), Apoptosis-Inducing Factor (AIF) and endonuclease G [30,31]. Subsequent activation of effector caspases leads to the proteolysis and typical morphological changes of apoptosis [32]. Although the molecular composition of the mPTP is not completely known, three components are suggested to be related to the MPTP (directly or indirectly): the outer membrane channel VDAC [33-35], the Adenine Nucleotide Translocator (ANT) [36] and cyclophilin-D [37]. However, studies with knockout animals have raised doubt about the involvement of ANT and VDAC in the MPTP $[38,39]$. In addition, recent studies with cyclophilin-D deficient cells strongly suggest that mPTP opening is a consequence, rather than the cause for apoptosis, and validate the original proposal that the mPTP is key in necrotic cell death (Figure 1) [37,40,41]. Furthermore, the observation that cytochrome $\mathrm{c}$ release can occur without the loss ofouter membrane integrity indicates that a more selective mechanism of permeabilization such as the formation of a pore in the outer membrane instead of membrane rupture is operating in apoptosis [42-45]. The MAC forms early in apoptosis in the mitochondrial outer membrane and provides a direct pathway for the release of cytochrome $c$ from the inter-membrane space into the cytosol. Bcl-2 family proteins tightly regulate the MAC and pro-apoptotic members of Bcl2 family such as Bak and Bax are components of this channel (Figure 1) $[31,42,43,45-47]$. However, the complete molecular structure of the MAC is not known and it is suggested that the MAC may contain additional components $[31,48]$. Both the MPTP and the MAC are potential therapeutic targets to induce cell death in malignancies and prevent cell death in degenerative and ischemia-associated pathologies. Indeed, NIM811 (a non-immunosuppressor cyclosporine-analogue) is reported to decrease liver injury and induce liver regeneration by inhibiting MPT after liver transplantation or massive hepatectomy $[49,50]$. NIM811 is also reported to attenuate cholestatic necrosis and apoptosis in BDL rats via inhibition of MPT [51]. Modulation of MPT in a multidrug-resistant hepatocellular carcinoma cell line with the selective MPT opener, Atractyloside Glycoside (ATR), was shown to increase apoptosis in these cells whereas the selective inhibitor of MPT, Cyclosporine A, had the opposite effect [52]. These data suggest that targeting MPT is a potential therapeutic strategy for different liver diseases.

Endoplasmic reticulum: Endoplasmic Reticulum (ER) stress is suggested to be an important mechanism in the pathogenesis of chronic liver diseases including NAFLD, ASH, viral hepatitis, druginduced liver injury, ischemia/reperfusion injury and cholestatic liver disease [53]. The ER is responsible for synthesis, folding, trafficking and maturation of proteins. Under pathologic conditions, the homeostatic equilibrium between the influx of the unfolded proteins and the folding capacity of the ER is disturbed. This leads to the activation of signal transduction pathways between the ER and other intracellular organelles to mediate cellular adaptation to new demands (Figure 2). These series of compensatory responses, termed Unfolded Protein Response (UPR), are conserved in the evolution to promote cellular survival [54]. In addition, glucose deprivation and the depletion of calcium stores can induce ER-stress [55-57]. Three membrane sensors in the ER mediate the ER-stress signal transduction: inositol-requiring enzyme-1a (IRE1 $\alpha$ ), Activating Transcription Factor (ATF) 6 and Protein kinase RNA-like Endoplasmic Reticulum Kinase (PERK) (Figure 2). These transmembrane sensors are kept inactivate as long as they are bound to the intraluminal chaperone Glucose-Regulated Protein 78 (GRP78) (Figure 2) [58,59]. IRE1 $\alpha$ is an endoribonuclease that promotes the splicing of X-box Binding Protein 1 (XBP1) mRNA, resulting in transcription of UPR elements and ER-stress response genes that control ER-Associated Protein Degradation (ERAD) and chaperones [60-62]. PERK induces phosphorylation of eukaryotic translation initiation factor-2 $\alpha$ subunit (eIF2 $\alpha$ ), thereby globally inhibiting protein synthesis [63]. PERK also regulates the transcription of ribosomal RNA via phosphorylation of eIF2 and increases the translation of ATF4. In turn, ATF4 binds to the cAMP-Response Element (CRE) resulting in the synthesis of C/EBP (CCAAT/enhancer binding protein) Homologous Protein (CHOP) [58,64,65]. Active ATF6 translocates to the nucleus and together with sXBP1 and ATF4, activate ER-stress response elements, UPR elements and CRE [66-68]. Upon ER-stress, GRP78 is displaced from the stress sensor, leading to the activation of these three ER-stress mediated signaling pathways (i.e. IRE1a, ATF6 and PERK) (Figure 2). Prolonged or unchecked ER-stress leads to steatosis, apoptosis and inflammation in the liver

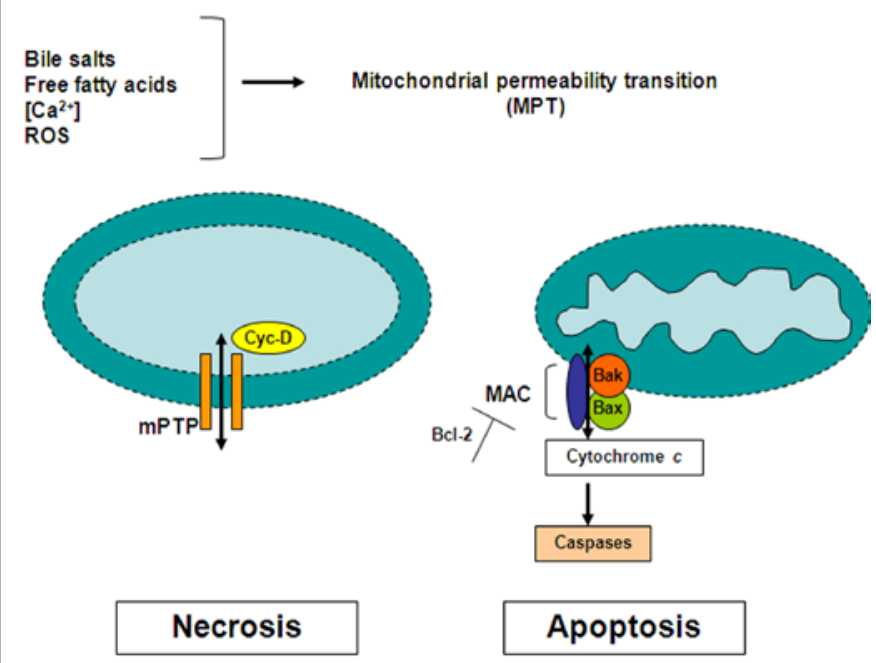

Figure 1: 

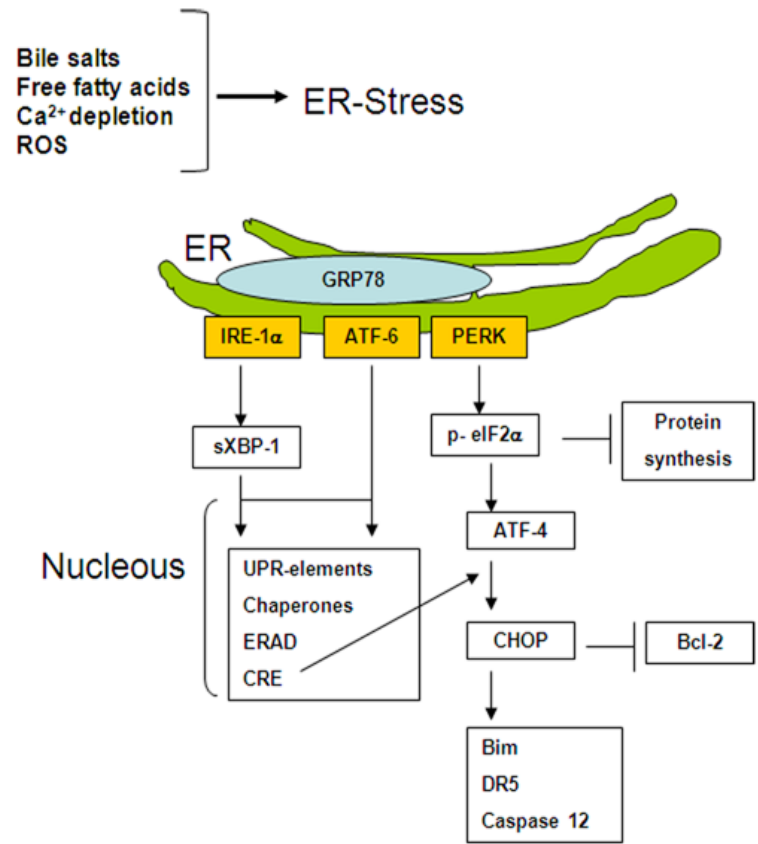

Apoptosis

Figure 2:

[53]. An important feature of the ER-stress response is increased $\mathrm{CHOP}$ expression leading to the activation of proapoptotic pathways [69]. Overexpression or microinjection of CHOP protein has been reported to promote cell cycle arrest and/or apoptosis [70,71]. CHOP can induce the expression of proapoptotic $\mathrm{BH} 3$-only protein Bim and the cell surface death receptor TRAIL receptor 2 (also known as death-receptor 5, DR5) and inhibit Bcl-2 transcription [72-74]. CHOPknockout mice are protected against alcohol-induced hepatocyte apoptosis after alcohol feeding as well as against bile salt-induced hepatocyte apoptosis after bile duct ligation [75,76]. Acetaminophen (APAP) intoxication has been observed to induce CHOP expression and to cause an intraluminal redox imbalance of the ER, resulting in hepatocyte apoptosis [77]. Importantly, the role of ER stress in APAPinduced necrosis is unknown. However, a role for ER stress in the early activation of JNK and in $\mathrm{Ca}^{2+}$-mediated mitochondrial permeability transition, both key factors in APAP-induced necrosis, could be considered $[78,79]$.

Several therapeutic interventions could modulate ER-stress for example chemical chaperones that ameliorate protein folding and antioxidants that counteract oxidative stress. The chemical chaperone 4-Phenylbutyrate (4PBA) is able to reduce the ER-stress response and decrease ER-associated caspase 12 activation in livers of mice undergoing ischemia-reperfusion injury [80]. However, since caspase 12 is only present in mice, ER-stress may activate other apoptotic pathways in human hepatocytes, such as $\mathrm{Ca}^{2+}$-mediated mitochondrial permeability transition. CHOP antagonism is also an obvious target for therapy as CHOP is involved in oxidative stress and apoptosis in hepatocytes. Improved protein folding would be beneficial in disorders of misfolded proteins such as alpha-1-antitrypsin deficiency. Thus, agents that ameliorate ER-stress by promoting adaptive UPR signaling or inhibiting ER-stress response-induced apoptosis offer a therapeutic opportunity. Since the ER-stress response has extensive cross-talk with other stress responses, therapeutics aimed at blunting the ER stress response may interrupt this inter-organelle cross-talk that operates in many liver diseases [53].

Lysosomes: Lysosomes are involved in necrotic, apoptotic and autophagic cell death. The key factor in determining the type of cell death is the magnitude of Lysosomal Membrane Permeabilization (LMP) and the amount of proteolytic enzymes released into the cytosol [81]. Massive breakdown of lysosomes results in unregulated necrosis, whereas selective permeabilization of lysosomes triggers apoptosis. Several mechanisms for the controlled permeabilization of lysosmes have been proposed (Figure 3). One theory includes the accumulation of lysosomotropic detergents such as sphingosine in the lysosomes, facilitating the release of lysosomal enzymes into the cytoplasm [82]. Another theory involves ROS-mediated lysosomal destabilization. In this theory, LMP is suggested to precede mitochondrial dysfunction, thereby creating a feedback loop between mitochondrial-derived ROS and LMP to control cell death (Figure 3). In addition, intralysosomal accumulation of free iron indirectly mediates lysosmal membrane damage via generation of ROS $[83,84]$. Translocation of proapoptotic members of the Bcl-2 family such as Bax and Bim to the lysosomes, leading to pore formation and membrane permeabilization (similar to their role in mitochondrial permeabilization) is also proposed as a mechanism for lysosomal leakage (Figure 3) [85-88]. LMP associated with cathepsin translocation may directly activate calpains and caspases, triggering classic MOMP- and caspase-dependent apoptosis and/or caspase-independent cell death [89]. Increased lysosomal enzyme activity (e.g., acidic phosphatase) is observed in patients with chronic liver diseases including chronic viral hepatitis, cirrhosis and hepatocellular carcinoma [90]. In addition, LMP and cathepsins have been implicated in cell death in several models of liver injury. For instance, it has been shown that intracellular levels of sphingosine in the liver increases after TNFa treatment, leading to LMP and apoptosis. Interestingly, TNF $\alpha$ or sphingosine could not induce LMP in hepatocytes from cathepsin-B knockout livers, suggesting that cathepsins may also be inducers of LMP. Cathepsins may directly induce LMP acting from the inside and/or outside of the lysosomes or they may participate in an amplification loop in which LMP induces cathepsin activation, and cathepsin then triggers further LMP (Figure 3) [88,91]. Free fatty acids and bile salts can also induce LMPdependent cell death [92-95]. Glycochenodexycholic acid (a cholestatic bile salt) induces LMP, cathepsin-B translocation, caspase activation and cell death in hepatocytes in animal models of cholestasis $[92,96]$.

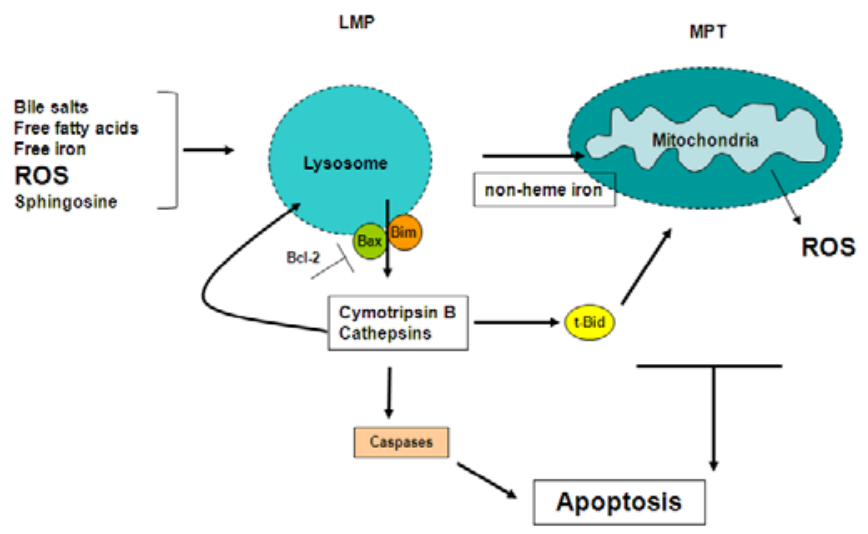

Figure 3: 
Excessive accumulation of saturated free fatty acids in the liver has been reported to directly induce mitochondrial dysfunction and oxidative stress via LMP and activation of cathepsin B [95]. Translocation of non-heme iron from lysosomes to the mitochondria is reported to play an important role in oxidative-stress induced hepatocellular damage, identifying this pathway as a potential therapeutic target to combat oxidative stress-mediated hepatotoxicity (Figure 3) [97]. Cymotrypsin $\mathrm{B}$, a lysosomal enzyme originally described in pancreas, was also found in rat liver lysosomes. Interestingly, Cymotrypsin B was reported to cleave the non-apoptotic Bid into pro-apoptotic Truncated Bid (tBid) at neutral $\mathrm{pH}$.tBid then translocates to mitochondria, leading to MOMP and cytochrome $\mathrm{c}$ release (Figure 3). Knockdown of Cymotrypsin $\mathrm{B}$ or pretreatment with the Cymotrypsin B inhibitor, N-p-tosyl-Lphenylalanine chloromethyl ketone, reduced TNFa-induced apoptosis in hepatocytes [98]. As noted before for ER-stress, it is important to appreciate that disturbance in redox status, steatosis, oxidative stress, inflammation and mitochondrial injury all affect LMP. LMP can activate interorganellar signaling pathways, death-receptor mediated signaling and lysosomal proteases such as cathepsin B. Therefore, therapeutics aimed at reducing LMP may interrupt all these signaling pathways, thereby reducing liver inflammation and hepatocyte damage.

\section{Receptor-mediated cell death}

Membrane death receptors: Death receptors belong to the TNF/ Nerve Growth Factor superfamily and are involved in death ligandmediated cell death. TNFa, Fas ligand (FasL) and Tumor Necrosis Factor-Related Apoptosis-Inducing Ligand (TRAIL) are death ligands that signal via binding to their membrane-bound receptors including: Fas, Tumor Necrosis Factor Receptor (TNFR1 and TNFR2), and TRAIL receptors (R1/DR4 and R2/DR5). Receptor-ligand binding triggers receptor trimerization at the cell surface, providing a platform at the cytoplasmic side of the plasma membrane (termed Death Domains) which recruits adaptor proteins such as Fas-Associated Death Domain (FADD). However, the exact composition of a functional TNFR as the initial trigger of signal transduction is a matter of dispute. Indeed, recent data suggest that a receptor dimer is a minimum functional unit and upon ligand induced-clustering of receptors large polymeric complexes assemble to induce signal transduction pathways $[99,100]$. The interaction between the Death Domains (DD) of death receptors and adaptor proteins leads to the activation of caspase- 8 and subsequent cleavage of Bid to $\mathrm{tBid}$. Translocation of tBid to mitochondria results in mitochondrial permeabilization and activation of the apoptotic cascades. In addition, TNF $\alpha$-induced Bid-dependent and TRAILinduced Bax-dependent LMP has been described. LMP then leads to cell death $[88,101]$. Although death receptors do not induce ER stress, ER stress-mediated regulation of TRAIL receptor (DR5) expression has been reported $[73,102]$. Therefore, interaction between death receptor signaling and intracellular organelles plays an important role in cell death (Figure 4). Hepatocytes in particular, characterized as type II cells, require the mitochondrial induced-apoptotic cascades coupling to the activation of death receptor induced-apoptotic pathways in order to conduct an effective apoptotic signal.

Several liver cells including hepatocytes express Fas (CD95/ Apo1) [103-105]. Fas is activated upon binding of membrane-bound FasL (mFasL) or soluble FasL (sFasL). mFasL is expressed on several immune cells including cytotoxic T lymphocytes and natural killer (NK) cells [106]. mFasL then activates Fas-mediated cell death, leading to the removal of unwanted hepatocytes such as virus-infected hepatocytes and cancer cells by immune cells [107]. While mFasL is a proapoptotic trigger, sFasL is an antagonist for mFasL-induced apoptosis. It was shown that T-cells of mice lacking sFasL are able to kill target cells via Fas-induced apoptosis whereas T-cells of mice lacking mFasL were incompetent to induce Fas-induced apoptosis [108]. Indeed conversion of $\mathrm{mFasL}$ to sFasL by metalloproteinase (a so-called shedding process) is a mechanism to prevent the killing of adjacent healthy cells by cytotoxic immune cells $[109,110]$. Nevertheless, excessive Fas-induced cell death leads to liver failure. Indeed, injection of Fas agonistic antibody to mice induces fulminant hepatic failure. In addition, it was shown that anti-apoptotic and pro-apoptotic Bcl-2 members regulate this toxicity [111-113]. Elevation of soluble FasL occurs in patients with acute liver failure (such as drug-induced liver injury and acetaminopheninduced liver injury), which may be a defensive mechanism of the liver to reduce the Fas-induced liver toxicity. In addition,FasL and/ or Fas receptor expression is increased in many chronic liver diseases including chronic viral hepatitis and alcoholic liver diseases [114-117]. In summary, Fas/FasL induced apoptotic cell death plays a crucial role in liver pathogenesis.

TNFR1 and TNFR2 are both expressed on hepatocytes, but only TNFR1 expresses a DD [118]. Importantly, TNFR1 activation in hepatocytes can trigger both apoptotic and survival signaling. TNFaexposure leads to the rapid formation of a DISC (Death Inducing Signaling Complex) composed of TNFa, the TNFR-Associated Death Domain Adaptor Molecule (TRADD), the Fas-Associated Death Domain Adaptor Molecule (FADD), caspase-8, TNFRAssociated Factor -2 (TRAF2) and Receptor-Interacting Protein (RIP). Interestingly, it was shown that TNFR1 and some DISC components also appear inside mitochondria within 30 minutes after TNFaexposure, suggesting that $\mathrm{TNF} \alpha$-mediated signaling includes the translocation of TNFR1 (and associated proteins) to mitochondria [119]. In contrast, TRADD suppresses apoptosis by recruiting RIP, TRAF2 and TRAF5. Immediate binding of RIP and TRAF2 to TRADD lead to the activation of Nuclear Factor- $\kappa \mathrm{B}(\mathrm{NF}-\kappa \mathrm{B})$ and transcriptional activation of pro-survival genes including $\mathrm{Bcl}-\mathrm{xL}, \mathrm{A1}$, XIAP and cFLIP $[120,121]$. TNFa/TNFR2 signaling is involved in the activation of hepatocyte DNA synthesis and proliferation as well as in the regulation of FasL-dependent clearance of virus infected hepatocytes by Cytotoxic T Lymphocytes (CTL) [122,123]. Interestingly, mice lacking both TNFR1 and TNFR2 are resistant to anti-Fas induced-fulminant hepatic failure [124]. These data suggest that TNFa/TNFRs interactions are critical for the proper functioning of CTL activity in the liver and clearance of infected and/or damaged hepatocytes.

TRAIL is emerging as a key mediator of hepatic injury during inflammatory disorders of the liver [125]. Early studies demonstrated that different cells have different sensitivity to TRAIL-induced cell death. Whereas cancer cells are sensitive to TRAIL-induced toxicity, normal (non-transformed) cells were resistant to its apoptosisinducing effects. Hence, TRAIL-induced selective cancer cell death without damage to the adjacent normal tissue was suggested to be an efficient anti-cancer therapy despite that many cancer cells are now considered as resistant to TRAIL induced-apoptosis [126,127]. Indeed, TRAIL, DR4 and DR5 (TRAIL receptors) messenger RNA are expressed at low levels in normal human liver and the expression of the receptors at the protein level is difficult to detect. However, emerging data indicate that DR4 and DR5 expression is up-regulated in several liver diseases such as steatosis and HCV- and HBV-infection [128131]. HIV and/or the ligation of HIV glycoprotein gp120 to CXCR4 
on hepatocytes also selectively increases DR5 expression and suggest that HIV infection renders hepatocytes more susceptible to apoptotic cell death in liver diseases associated with enhanced TRAIL expression such as HBV, HCV or steatohepatitis [132]. Increased DR5 expression in experimental models of NASH is associated with the activation of p53 and ER-stress induced CHOP expression by free fatty acids such as palmitate $[133,134]$. In addition, bile acids can increase DR5 expression and inhibit cFLIP (inhibitor of DR5-induced signaling) function, thereby sensitize hepatocytes to TRAIL mediated cell death in cholestatic livers $[135,136]$. Thus, the safety of TRAIL administration to humans with underlying liver disease is questionable. The development of selective DR4 agonistic antibodies to treat cancer in patients with underlying liver diseases could be an attractive strategy, considering the possibility of DR5-dependent TRAIL toxicity in liver diseases.

In summary, excessive generation of inflammatory mediators and activation of death receptor-mediated apoptotic pathways can exacerbate underlying liver diseases. Therefore, therapies targeting death receptor-mediated hepatotoxicity in combination with efforts to remove the cause of the disease (e.g., virus, toxic bile acids, free fatty acids and drugs) may be a beneficial strategy in the treatment of liver diseases.

Epidermal growth factor receptor: The epidermal growth factor receptors (EGFR; ErbB-1; HER1 in humans) are the cellsurface receptors for members of the Epidermal Growth Factor Family (EGF-family) of extracellular protein ligands. The EGFR is a member of the ErbB family of receptors, a subfamily of four closely related receptor tyrosine kinases: EGFR (ErbB-1), HER2/c-neu (ErbB-2), Her 3 (ErbB3) and Her 4 (ErbB-4) [137]. Growth factor receptors such as the EGFR are involved in both cell proliferation and cell death in the liver [138]. EGF functions as an endocrine factor. It is produced by a variety of cells and EGF/EGFR interaction is essential for liver regeneration [139]. Ligand-dependent EGFR activation also plays a role in hepatic tumorigenesis and EGFR-targeting agents such as monoclonal antibodies (e.g., cetuximab and panitumumab) and tyrosine kinase inhibitors (e.g., gefitinib and erlotinib) are suggested in the treatment of liver carcinomas [140,141]. In addition to ligand-dependent EGFR activation, ligand-independent EGFR activation in the liver has been described. For instance, hydrophobic bile acids induce Reactive Oxygen Species (ROS)-dependent EGFR tyrosine phosphorylation in hepatocytes, leading to the activation of downstream MitogenActivated Protein Kinases (MAPK) [14]. Hydrophobic bile acids also induce Extracellular Kinase Regulated (ERK)-dependent Hepatic Stellate Cell (HSC) proliferation via ROS-dependent EGFR activation [142]. As described above, ligand-independent EGFR activation plays an important role in liver pathogenesis. In hepatocytes, ligandindependent EGFR activation also contributes to apoptosis [138]. Several mechanisms for ligand-independent EGFR activation have been described such as EGFR transactivation by Fas ligand (FasL) [143,144], hydrophobic bile salts (deoxycholate, glychocenodeoxycholate, etc) or hyperosmolarity $[14,143,144]$ (Figure 4). Ligand-independent activation of EGFR, a process that requires ROS-dependent Yes activation (a non-receptor tyrosine kinase protein of Src kinase family) followed by Yes-mediated EGFR transactivation [143-147], follows JNK-dependent EGFR/Fas association. EGFR/Fas association results in EGFR-mediated tyrosine phosphorylation of Fas (death receptor), leading to Fas oligomerization, membrane translocation, DISC formation and execution of apoptosis $[143,144,148]$.
These data suggest that agents that inhibit ligand-independent activation of EGFR such as tyrosine kinase inhibitors may have substantial anti-apoptotic effects in hepatocytes. Interestingly, recent evidence suggests that the EGFR can also function as a host cofactor for HCV entry and tyrosine kinase inhibitors show substantial antiviral activity [149]. Chronic viral hepatitis is associated with activation of inflammatory mediators and accumulation of immune cells in the liver, which can induce hepatocyte apoptosis/necrosis in non-infected hepatocytes via activation of death-receptor signaling pathways. Thus inhibition of receptor tyrosine kinase (such as EGFR) may constitute an attractive novel approach in the treatment of chronic liver diseases, in particular chronic viral hepatitis due to their antiviral activity and anti-apoptotic effects in healthy hepatocytes.

G-protein coupled receptors: GPCRs are the largest family of membrane proteins. More than 300 GPCRs have been reported in humans and rodents [150]. GPCRs transduce extracellular signals to intracellular effector pathways. Upon activation by agonists, GPCRs activate heterotrimeric G-proteins $\left(G_{\alpha} \beta \gamma\right)$. These subunits subsequently activate second messengers (e.g. cAMP, $\mathrm{Ca}^{2+}$ and protein kinases), relaying the GPCR induced-signal to the intracellular targets. Heterotrimeric G-proteins are divided into 4 families (i.e., Gas, Gai, Gaq/11 and Ga12/13) based on the $G_{\alpha}$ subunit sequence and signaling activity [151]. Many GPCRs such as lysophosphatidic acid (LPA), sphingosine-1 phosphate (S1P) and orexin (OXR) receptors are involved in the regulation of apoptosis in cancer cells [152-154]. Signaling components, acting downstream of the GPCRs or G-proteins (e.g., arrestin and adaptor protein 2) may mediate anti-apoptotic events following stimulation of GPCRs [155,156]. Activation of GPCRs regulates apoptosis in cancer cells via interaction with different intracellular regulators of apoptosis such as MAPKs, NF- $\kappa B$ and p53associated pathways [157]. E.g., LPA-dependent signaling decreases the nuclear localization and cellular abundance of p53, leading to resistance of lung carcinoma cells to apoptosis [158]. Activation of the receptors for LPA, ET1 (endothelin) and angiotensin II can activate NF- $\kappa B$-regulated pathways. NF- $\kappa B$ then mediates either antiapoptotic or pro-apoptotic responses, depending on the stimulus and the cell type [120,159-162]. In the liver, activation of GPCRs also mediates both apoptotic and anti-apoptotic responses. E.g., S1P receptors mediate both apoptotic and anti-apoptotic pathways in human hepatic myofibroblasts [163]. Free fatty acids such as palmitic

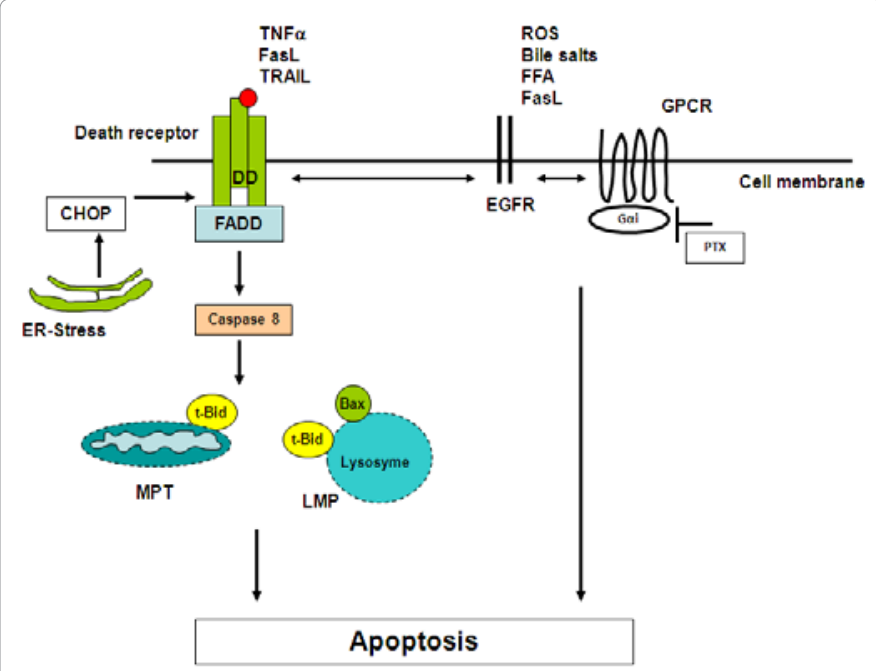

Figure 4: 
acid mediate apoptosis in hepatocytes via phospholipase A2 (PLA $)$ / lysophosphatidylcholine (LPC)/LPA-dependent signaling [164]. However, the exact signaling pathways downstream of GPCRs that regulate apoptosis in hepatocytes are yet unknown. Nevertheless, some GPCR-based drugs show potent anti-tumor efficacy e.g. the endothelin A receptor antagonists -ZD4054 and atrasentan [157,165167]. GPCR-based drugs may also show therapeutic benefits in the regulation of apoptosis in chronic liver diseases and liver tumors. We have shown that Pertussis Toxin (PTX), an inhibitor of $\mathrm{G}_{\alpha}$-protein, protects hepatocytes but not hepatocellular carcinoma cells against bile salt-induced and cytokine-induced apoptosis, suggesting a cross-talk between GPCR and EGFR in hepatocyte apoptosis (Figure 4) [168]. Activating death receptor-mediated apoptosis in cancer cells by death ligands is suggested as an effective therapeutic strategy in the treatment of hepatocellular carcinoma [169] but this strategy may lead to the induction of apoptosis in adjacent normal hepatocytes. Therefore, an adjuvant anti-apoptotic therapy that will inhibit cell death in normal hepatocytes but has no effect on cancer cells may prevent excessive liver damage. Our data suggest that GPCR/G $\mathrm{G}_{\mathrm{ai}}$-based therapeutic strategies may serve as the anti-apoptotic adjuvant therapy, protecting normal tissue against inflammation, bile salt and/or drug-induced cell death.

\section{Conclusions}

Understanding the cellular mechanisms that control death in hepatocytes is of clinical and scientific importance in the development of novel therapies. Hepatocyte cell death appears to be at the crossroads of several cellular mechanisms rather than the end-point of a linear cascade of events. One particular toxic stimulus may simultaneously promote the activation of several types of membrane-bound receptors as well as organelle-mediated signaling pathways, leading to apoptosis. In addition, several toxic stimuli often play a role in the pathogenesis of chronic liver diseases (e.g., free fatty acids and inflammatory mediators in NASH). Thus, anti-apoptotic therapeutics aimed at one particular pathway may be more effective when used in combination with other interventions.

\section{References}

1. Guicciardi ME, Gores GJ (2010) Apoptosis as a mechanism for liver disease progression. Semin Liver Dis 30: 402-410.

2. Malhi H, Gores GJ, Lemasters JJ (2006) Apoptosis and necrosis in the liver: A tale of two deaths? Hepatology 43: S31-S44.

3. Schoemaker MH, Moshage $\mathrm{H}$ (2004) Defying death: The hepatocyte's survival kit. Clin Sci (Lond) 107: 13-25.

4. Golstein P, Kroemer G (2007) Cell death by necrosis: Towards a molecular definition. Trends Biochem Sci 32: 37-43.

5. Nagata S, Hanayama R, Kawane K (2010) Autoimmunity and the clearance of dead cells. Cell 140: 619-630.

6. Hotchkiss RS, Strasser A, McDunn JE, Swanson PE (2009) Cell death. The New England Journal of Medicine 361: 1570-1583.

7. Malhi H, Guicciardi ME, Gores GJ (2010) Hepatocyte death: A clear and present danger. Physiol Rev 90: 1165-1194.

8. Feldstein AE, Canbay A, Angulo P, Taniai M, Burgart LJ, et al. (2003) Hepatocyte apoptosis and fas expression are prominent features of human nonalcoholic steatohepatitis. Gastroenterology 125: 437-443.

9. Ribeiro PS, Cortez-Pinto H, Sola S, Castro RE, Ramalho RM, et al. (2004) Hepatocyte apoptosis, expression of death receptors, and activation of NFkappaB in the liver of nonalcoholic and alcoholic steatohepatitis patients. Am J Gastroentero 99: 1708-1717.

10. Tamimi TI, Elgouhari HM, Alkhouri N, Yerian LM, Berk MP, et al. (2011) An apoptosis panel for nonalcoholic steatohepatitis diagnosis. J Hepatol 54: 12241229.
11. Yagmur E, Trautwein C, Leers MP, Gressner AM, Tacke F (2007) Elevated apoptosis-associated cytokeratin 18 fragments (CK18Asp386) in serum of patients with chronic liver diseases indicate hepatic and biliary inflammation. Clin Biochem 40: 651-655.

12. Canbay A, Feldstein AE, Higuchi H, Werneburg N, Grambihler A, et al. (2003) Kupffer cell engulfment of apoptotic bodies stimulates death ligand and cytokine expression. Hepatology 38: 1188-1198.

13. Eum HA, Billiar TR (2011) TNF/TNF receptor 1-mediated apoptosis in hepatocytes. Adv Exp Med Biol 691: 617-624.

14. Qiao L, Studer E, Leach K, McKinstry R, Gupta S, et al. (2001) Deoxycholic acid (DCA) causes ligand-independent activation of epidermal growth factor receptor (EGFR) and FAS receptor in primary hepatocytes: Inhibition of EGFR/ mitogen-activated protein kinase-signaling module enhances DCA-induced apoptosis. Mol Biol Cell 12: 2629-2645.

15. Friedman SL (2008) Mechanisms of hepatic fibrogenesis. Gastroenterology 134: 1655-1669.

16. Dranoff JA, Wells RG (2010) Portal fibroblasts: Underappreciated mediators of biliary fibrosis. Hepatology 51: 1438-1444.

17. Canbay A, Taimr P, Torok N, Higuchi H, Friedman S, et al. (2003) Apoptotic body engulfment by a human stellate cell line is profibrogenic. Lab Invest 83 655-663.

18. Jiang JX, Mikami K, Venugopal S, Li Y, Torok NJ (2009) Apoptotic body engulfment by hepatic stellate cells promotes their survival by the JAK/STAT and Akt/NF-kappaB-dependent pathways. J Hepatol 51: 139-148.

19. Calvaruso V, Craxi A (2011) Fibrosis in chronic viral hepatitis. Best Practice \& Research Clinical Gastroenterology 25: 219-230.

20. Anstee QM, Concas D, Kudo H, Levene A, Pollard J, et al. (2010) Impact of pan-caspase inhibition in animal models of established steatosis and nonalcoholic steatohepatitis. J Hepatol 53: 542-550.

21. Amaral JD, Viana RJ, Ramalho RM, Steer CJ, Rodrigues CM (2009) Bile acids: Regulation of apoptosis by ursodeoxycholic acid. J Lipid Res 50: 1721-1734.

22. Masuoka HC, Guicciardi ME, Gores GJ (2009) Caspase inhibitors for the treatment of hepatitis C. Clin Liver Dis 13: 467-475.

23. Serviddio G, Bellanti F, Sastre J, Vendemiale G, Altomare E (2010) Targeting mitochondria: A new promising approach for the treatment of liver diseases. Curr Med Chem 17: 2325-2337.

24. Kroemer G, Reed JC. (2000) Mitochondrial control of cell death. Nat Med 6 513-519.

25. Lemasters JJ (1999) V. necrapoptosis and the mitochondrial permeability transition: Shared pathways to necrosis and apoptosis. Am J Physiol 276: G1G6.

26. Tsujimoto $Y$, Nakagawa T, Shimizu S (2006) Mitochondrial membrane permeability transition and cell death. Biochimica Et Biophysica Acta 1757 1297-1300.

27. Kim JS, He L, Lemasters JJ (2003) Mitochondrial permeability transition: A common pathway to necrosis and apoptosis. Biochem Biophys Res Commun 304: 463-470.

28. Sola S, Aranha MM, Steer CJ, Rodrigues CM (2007) Game and players: Mitochondrial apoptosis and the therapeutic potential of ursodeoxycholic acid Curr Issues Mol Biol 9: 123-138.

29. Kinnally KW, Peixoto PM, Ryu SY, Dejean LM (2011) Is mPTP the gatekeeper for necrosis, apoptosis, or both? Biochim Biophy Acta 1813: 616-622.

30. Saelens X, Festjens N, Vande Walle L, van Gurp M, van Loo G, et al. (2004) Toxic proteins released from mitochondria in cell death. Oncogene 23: 2861 2874.

31. Kinnally KW, Antonsson B (2007) A tale of two mitochondrial channels, MAC and PTP, in apoptosis. Apoptosis 12: 857-868.

32. Chowdhury I, Tharakan B, Bhat GK (2008) Caspases - an update. Comparative Biochemistry and Physiology. Part B: Biochemistry \& Molecular Biology 151: $10-27$.

33. Kusano T, Tateda C, Berberich T, Takahashi Y (2009) Voltage-dependent anion channels: Their roles in plant defense and cell death. Plant Cell Rep 28 1301-1308. 
Citation: Karimian G, Faber KN, Moshage H (2013) Hepatocyte Apoptosis at the Interplay of Intracellular Organelles and Membrane-Bound Receptors: Targets for Therapy. Clin Exp Pharmacol S3:002. doi:10.4172/2161-1459.S3-002

Page 7 of 10

34. Krestinina OV, Grachev DE, Odinokova IV, Reiser G, Evtodienko YV, et al. (2009) Effect of peripheral benzodiazepine receptor (PBR/TSPO) ligands on opening of $\mathrm{Ca} 2+-$ induced pore and phosphorylation of 3.5-kDa polypeptide in rat brain mitochondria. Biochemistry 74: 421-429.

35. Tomasello F, Messina A, Lartigue L, Schembri L, Medina C, et al. (2009) Outer membrane VDAC1 controls permeability transition of the inner mitochondrial membrane in cellulo during stress-induced apoptosis. Cell Research 19: 13631376.

36. Halestrap AP (2004) Mitochondrial permeability: Dual role for the ADP/ATP translocator? Nature 430: $1 \mathrm{p}$ following 983.

37. Baines CP, Kaiser RA, Purcell NH, Blair NS, Osinska H, et al. (2005) Loss of cyclophilin $D$ reveals a critical role for mitochondrial permeability transition in cell death. Letters to Nature 434: 658-662.

38. Kokoszka JE, Waymire KG, Levy SE, Sligh JE, Cai J, et al. (2004) The ADP/ ATP translocator is not essential for the mitochondrial permeability transition pore. Nature 427: 461-465.

39. Baines CP, Kaiser RA, Sheiko T, Craigen WJ, Molkentin JD (2007) Voltagedependent anion channels are dispensable for mitochondrial-dependent cell death. Nat Cell Biol 9: 550-555.

40. 40. Crompton M, Ellinger $H$, Costi A (1988) Inhibition by cyclosporin A of a $\mathrm{Ca} 2+-d e p e n d e n t$ pore in heart mitochondria activated by inorganic phosphate and oxidative stress. Biochem J 255: 357-360.

41. Nakagawa T, Shimizu S, Watanabe T, Yamaguchi O, Otsu K, et al. (2005) Cyclophilin D-dependent mitochondrial permeability transition regulates some necrotic but not apoptotic cell death. Nature 434: 652-658.

42. De Giorgi F, Lartigue L, Bauer MK, Schubert A, Grimm S, et al. (2002) The permeability transition pore signals apoptosis by directing bax translocation and multimerization. The FASEB J 16: 607-609.

43. Dejean LM, Martinez-Caballero S, Guo L, Hughes C, Teijido O, et al. (2005) Oligomeric bax is a component of the putative cytochrome $c$ release channel MAC, mitochondrial apoptosis-induced channel. Mol Biol Cell 16: 2424-2432.

44. Pavlov EV, Priault M, Pietkiewicz D, Cheng EH, Antonsson B, et al. (2001) A novel, high conductance channel of mitochondria linked to apoptosis in mammalian cells and bax expression in yeast. J Cell Biol 155: 725-731.

45. Martinez-Caballero S, Dejean LM, Jonas EA, Kinnally KW (2005) The role of the mitochondrial apoptosis induced channel MAC in cytochrome $\mathrm{c}$ release. $J$ Bioenerg Biomembr 37: 155-164.

46. Dejean LM, Martinez-Caballero S, Manon S, Kinnally KW (2006) Regulation of the mitochondrial apoptosis-induced channel, MAC, by BCL-2 family proteins. Biochim Biophys Acta 1762: 191-201.

47. Werner AB, de Vries E, Tait SW, Bontjer I, Borst J (2002) Bcl-2 family member bfl-1/A1 sequesters truncated bid to inhibit is collaboration with pro-apoptotic bak or bax. J Biol Chem 277: 22781-22788.

48. Antonsson B, Montessuit S, Sanchez B, Martinou JC (2001) Bax is present as a high molecular weight oligomer/complex in the mitochondrial membrane of apoptotic cells. J Biol Chem 276: 11615-11623.

49. Zhong Z, Theruvath TP, Currin RT, Waldmeier PC, Lemasters JJ (2007) NIM811, a mitochondrial permeability transition inhibitor, prevents mitochondrial depolarization in small-for-size rat liver grafts. Am J Transplant 7: 1103-1111.

50. Theruvath TP, Zhong Z, Pediaditakis P, Ramshesh VK, Currin RT, et al. (2008) Minocycline and N-methyl-4-isoleucine cyclosporin (NIM811) mitigate storage/ reperfusion injury after rat liver transplantation through suppression of the mitochondrial permeability transition. Hepatology 47: 236-246.

51. Rehman H, Ramshesh VK, Theruvath TP, Kim I, Currin RT, et al. (2008) NIM811 (N-methyl-4-isoleucine cyclosporine), a mitochondrial permeability transition inhibitor, attenuates cholestatic liver injury but not fibrosis in mice. $J$ Pharmacol Exp Ther 327: 699-706.

52. Ling X, Zhou Y, Li SW, Yan B, Wen L (2010) Modulation of mitochondrial permeability transition pore affects multidrug resistance in human hepatocellular carcinoma cells. Int J Biol Sci 6: 773-783.

53. Dara L, Ji C, Kaplowitz N (2011) The contribution of endoplasmic reticulum stress to liver diseases. Hepatology 53: 1752-1763.

54. Mori K (2009) Signalling pathways in the unfolded protein response: Development from yeast to mammals. J Biochem 146: 743-750.
55. Badiola N, Penas C, Minano-Molina A, Barneda-Zahonero B, Fado R, et al (2011) Induction of ER stress in response to oxygen-glucose deprivation of cortical cultures involves the activation of the PERK and IRE-1 pathways and of caspase-12. Cell Death Dis 2: e149.

56. Ikesugi K, Mulhern ML, Madson CJ, Hosoya K, Terasaki T, et al. (2006) Induction of endoplasmic reticulum stress in retinal pericytes by glucose deprivation. Curr Eye Res 31: 947-953.

57. Mekahli D, Bultynck G, Parys JB, De Smedt H, Missiaen L (2011) Endoplasmicreticulum calcium depletion and disease. Cold Spring Harb Perspectives Biol 3.

58. Bertolotti A, Zhang Y, Hendershot LM, Harding HP, Ron D (2000) Dynamic interaction of $\mathrm{BiP}$ and $\mathrm{ER}$ stress transducers in the unfolded-protein response. Nat Cell Biol 2: 326-332.

59. Shen J, Chen X, Hendershot L, Prywes R (2002) ER stress regulation of ATF6 localization by dissociation of BiP/GRP78 binding and unmasking of golg localization signals. Dev Cell 3: 99-111.

60. Uemura A, Oku M, Mori K, Yoshida H (2009) Unconventional splicing of XBP1 mRNA occurs in the cytoplasm during the mammalian unfolded protein response. J Cell Sci 122: 2877-2886.

61. Korennykh AV, Egea PF, Korostelev AA, Finer-Moore J, Zhang C, et al. (2009) The unfolded protein response signals through high-order assembly of Ire1. Nature 457: 687-693.

62. Lee AH, Iwakoshi NN, Glimcher LH (2003) XBP-1 regulates a subset of endoplasmic reticulum resident chaperone genes in the unfolded protein response. Mol Cell Biol 23: 7448-7459.

63. Shi Y, Vattem KM, Sood R, An J, Liang J, et al. (1998) Identification and characterization of pancreatic eukaryotic initiation factor 2 alpha-subunit kinase, PEK, involved in translational control. Mol Cell Biol 18: 7499-7509.

64. DuRose JB, Scheuner D, Kaufman RJ, Rothblum LI, Niwa M (2009) Phosphorylation of eukaryotic translation initiation factor 2alpha coordinates rRNA transcription and translation inhibition during endoplasmic reticulum stress. Mol Cell Biol 29: 4295-4307.

65. Lu PD, Harding HP, Ron D (2004) Translation reinitiation at alternative open reading frames regulates gene expression in an integrated stress response. $J$ Cell Biol 167: 27-33.

66. Shen J, Chen X, Hendershot L, Prywes R (2002) ER stress regulation of ATF6 localization by dissociation of BiP/GRP78 binding and unmasking of golgi localization signals. Dev Cell 3: 99-111.

67. Lee K, Tirasophon W, Shen X, Michalak M, Prywes R, et al. (2002) IRE1mediated unconventional mRNA splicing and S2P-mediated ATF6 cleavage merge to regulate XBP1 in signaling the unfolded protein response. Genes Dev 16: 452-466.

68. Mori K (2010) Divest yourself of a preconceived idea: Transcription factor ATF6 is not a soluble protein! Mol Biol Cell 21: 1435-1438.

69. Oyadomari S, Mori M (2004) Roles of CHOP/GADD153 in endoplasmic reticulum stress. Cell Death Differ 11: 381-9.

70. Matsumoto M, Minami M, Takeda K, Sakao Y, Akira S (1996) Ectopic expression of CHOP (GADD153) induces apoptosis in M1 myeloblastic leukemia cells. FEBS Lett 395: 143-147.

71. Barone MV, Crozat A, Tabaee A, Philipson L, Ron D (1994) CHOP (GADD153) and its oncogenic variant, TLS-CHOP, have opposing effects on the induction of $\mathrm{G} 1 / \mathrm{S}$ arrest. Genes Dev 8: 453-464.

72. Puthalakath H, O'Reilly LA, Gunn P, Lee L, Kelly PN, et al. (2007) ER stress triggers apoptosis by activating BH3-only protein bim. Cell 129: 1337-1349.

73. Yamaguchi $\mathrm{H}$, Wang HG (2004) CHOP is involved in endoplasmic reticulum stress-induced apoptosis by enhancing DR5 expression in human carcinoma cells. J Biol Chem 279: 45495-45502.

74. McCullough KD, Martindale JL, Klotz LO, Aw TY, Holbrook NJ (2001) Gadd153 sensitizes cells to endoplasmic reticulum stress by down-regulating Bcl2 and perturbing the cellular redox state. Mol Cell Biol 21: 1249-1259.

75. Tamaki N, Hatano E, Taura K, Tada M, Kodama Y, et al. (2008) CHOP deficiency attenuates cholestasis-induced liver fibrosis by reduction of hepatocyte injury Am J Physiol Gastrointest Liver Physiol 294: G498-505.

76. Ji C, Mehrian-Shai R, Chan C, Hsu YH, Kaplowitz N (2005) Role of CHOP 
Citation: Karimian G, Faber KN, Moshage H (2013) Hepatocyte Apoptosis at the Interplay of Intracellular Organelles and Membrane-Bound Receptors: Targets for Therapy. Clin Exp Pharmacol S3:002. doi:10.4172/2161-1459.S3-002

Page 8 of 10

in hepatic apoptosis in the murine model of intragastric ethanol feeding. Alcoholism, Clin Exp Res 29: 1496-1503.

77. Benali-Furet NL, Chami M, Houel L, De Giorgi F, Vernejoul F, et al. (2005) Hepatitis $C$ virus core triggers apoptosis in liver cells by inducing ER stress and ER calcium depletion. Oncogene 24: 4921-4933.

78. Kon K, Kim JS, Jaeschke H, Lemasters JJ (2004) Mitochondrial permeability transition in acetaminophen-induced necrosis and apoptosis of cultured mouse hepatocytes. Hepatology 40: 1170-1179.

79. Henderson NC, Pollock KJ, Frew J, Mackinnon AC, Flavell RA, et al. (2007) Critical role of c-jun (NH2) terminal kinase in paracetamol- induced acute liver failure. Gut 56: 982-990.

80. Vilatoba M, Eckstein C, Bilbao G, Smyth CA, Jenkins S, et al. (2005) Sodium 4-phenylbutyrate protects against liver ischemia reperfusion injury by inhibition of endoplasmic reticulum-stress mediated apoptosis. Surgery 138: 342-351.

81. Li W, Yuan X, Nordgren G, Dalen H, Dubowchik GM, et al. (2000) Induction of cell death by the lysosomotropic detergent MSDH. FEBS Lett 470: 35-39.

82. Kagedal K, Zhao M, Svensson I, Brunk UT (2001) Sphingosine-induced apoptosis is dependent on lysosomal proteases. Biochemical J 359: 335-343.

83. Terman A, Kurz T, Gustafsson B, Brunk UT (2006) Lysosomal labilization. IUBMB Life 58: 531-539.

84. Terman A, Gustafsson B, Brunk UT (2006) The lysosomal-mitochondrial axis theory of postmitotic aging and cell death. Chem Biol Interact 163: 29-37.

85. Zhao M, Eaton JW, Brunk UT (2001) Bcl-2 phosphorylation is required for inhibition of oxidative stress-induced lysosomal leak and ensuing apoptosis. FEBS Lett 509: 405-412.

86. Zhao M, Eaton JW, Brunk UT (2000) Protection against oxidant-mediated lysosomal rupture: A new anti-apoptotic activity of bcl-2? FEBS Lett 485: 104108.

87. Kagedal K, Johansson AC, Johansson U, Heimlich G, Roberg K, et al. (2005) Lysosomal membrane permeabilization during apoptosis--involvement of bax? Int J Exp Pathol 86: 309-321.

88. Werneburg NW, Guicciardi ME, Bronk SF, Kaufmann SH, Gores GJ (2007) Tumor necrosis factor-related apoptosis-inducing ligand activates a lysosomal pathway of apoptosis that is regulated by bcl-2 proteins. J Biol Chem 282: 28960-28970.

89. Boya P, Kroemer G (2008) Lysosomal membrane permeabilization in cell death. Oncogene 27: 6434-6451.

90. Kyaw A, Aung T, Htut T, Myint H, Tin KM (1983) Lysosomal enzyme activities in normals and in patients with chronic liver diseases. Clin Chim Acta 131: 317-323.

91. Werneburg NW, Guicciardi ME, Bronk SF, Gores GJ (2002) Tumor necrosis factor-alpha-associated lysosomal permeabilization is cathepsin B dependent. Am J Physiol Gastrointest Liver Physiol 283: G947-G956.

92. Roberts LR, Kurosawa H, Bronk SF, Fesmier PJ, Agellon LB, et al. (1997) Cathepsin B contributes to bile salt-induced apoptosis of rat hepatocytes. Gastroenterology 113: 1714-1726.

93. Feldstein AE, Werneburg NW, Canbay A, Guicciardi ME, Bronk SF, et al. (2004) Free fatty acids promote hepatic lipotoxicity by stimulating TNF-alpha expression via a lysosomal pathway. Hepatology 40: 185-194.

94. Feldstein AE, Werneburg NW, Li Z, Bronk SF, Gores GJ (2006) Bax inhibition protects against free fatty acid-induced lysosomal permeabilization. Am J Physiol Gastrointest Liver Physiol 290: G1339-G1346.

95. Li Z, Berk M, Mclntyre TM, Gores GJ, Feldstein AE (2008) The lysosomalmitochondrial axis in free fatty acid-induced hepatic lipotoxicity. Hepatology 47: 1495-1503.

96. Canbay A, Guicciardi ME, Higuchi H, Feldstein A, Bronk SF, et al. (2003) Cathepsin B inactivation attenuates hepatic injury and fibrosis during cholestasis. J Clin Invest 112: 152-159.

97. Uchiyama A, Kim JS, Kon K, Jaeschke H, Ikejima K, et al. (2008) Translocation of iron from lysosomes into mitochondria is a key event during oxidative stressinduced hepatocellular injury. Hepatology 48: 1644-1654.

98. Miao Q, Sun Y, Wei T, Zhao X, Zhao K, et al. (2008) Chymotrypsin B cached in rat liver lysosomes and involved in apoptotic regulation through a mitochondrial pathway. J Biol Chem 283: 8218-8228.

99. Branschadel M, Aird A, Zappe A, Tietz C, Krippner-Heidenreich A, et al. (2010) Dual function of cysteine rich domain (CRD) 1 of TNF receptor type 1 Conformational stabilization of CRD2 and control of receptor responsiveness. Cell Signal 22: 404-414.

100.Lewis AK, Valley CC, Sachs JN (2012) TNFR1 signaling is associated with backbone conformational changes of receptor dimers consistent with overactivation in the R92Q TRAPS mutant. Biochemistry 51: 6545-6555.

101. Guicciardi ME, Bronk SF, Werneburg NW, Gores GJ (2007) cFLIPL prevents TRAIL-induced apoptosis of hepatocellular carcinoma cells by inhibiting the lysosomal pathway of apoptosis. Am J Physiol Gastrointest Liver Physiol 292: G1337-G1346.

102. He Q, Luo X, Jin W, Huang Y, Reddy MV, et al. (2008) Celecoxib and a novel COX-2 inhibitor ON09310 upregulate death receptor 5 expression via GADD153/CHOP. Oncogene 27: 2656-2660.

103. Muschen M, Warskulat U, Douillard P, Gilbert E, Haussinger D (1998) Regulation of CD95 (APO-1/Fas) receptor and ligand expression by lipopolysaccharide and dexamethasone in parenchymal and nonparenchymal rat liver cells. Hepatology 27: 200-208.

104. Cardier JE, Schulte T, Kammer H, Kwak J, Cardier M (1999) Fas (CD95 APO-1) antigen expression and function in murine liver endothelial cells: Implications for the regulation of apoptosis in liver endothelial cells. FASEB J 13: 1950-1960.

105. Ueno Y, Ishii M, Yahagi K, Mano Y, Kisara N, et al. (2000) Fas-mediated cholangiopathy in the murine model of graft versus host disease. Hepatology 31: 966-974.

106. Lettau M, Paulsen M, Kabelitz D, Janssen O (2008) Storage, expression and function of fas ligand, the key death factor of immune cells. Curr Med Chem 15: 1684-1696.

107. Swain MG (2008) Hepatic NKT cells: Friend or foe? Clin Sci 114: 457-466.

108. O'Reilly LA, Tai L, Lee L, Kruse EA, Grabow S, et al. (2009) Membrane-bound fas ligand only is essential for fas-induced apoptosis. Nature 461: 659-663.

109. Tanaka M, Itai T, Adachi M, Nagata S (1998) Downregulation of fas ligand by shedding. Nat Med 4: 31-36

110. Schneider P, Holler N, Bodmer JL, Hahne M, Frei K, et al. (1998) Conversion of membrane-bound fas(CD95) ligand to its soluble form is associated with downregulation of its proapoptotic activity and loss of liver toxicity. The $\mathrm{J}$ Exp Med 187: 1205-1213.

111. Ogasawara J, Watanabe-Fukunaga R, Adachi M, Matsuzawa A, Kasugai T, et al. (1993) Lethal effect of the anti-fas antibody in mice. Nature 364: 806-809.

112. Lacronique $\mathrm{V}$, Mignon A, Fabre M, Viollet B, Rouquet N, et al. (1996) Bcl-2 protects from lethal hepatic apoptosis induced by an anti-fas antibody in mice. Nat Med 2: 80-86.

113. Yin XM, Wang K, Gross A, Zhao Y, Zinkel S, et al. (1999) Bid-deficient mice are resistant to fas-induced hepatocellular apoptosis. Nature 400: 886-891.

114. Rutherford AE, Hynan LS, Borges CB, Forcione DG, Blackard JT, et al. (2007) Serum apoptosis markers in acute liver failure: A pilot study. Clin Gastroenterol Hepatology 5: 1477-1483.

115. Ryo K, Kamogawa Y, Ikeda I, Yamauchi K, Yonehara S, et al. (2000) Significance of fas antigen-mediated apoptosis in human fulminant hepatic failure. Am J Gastroenterol 95: 2047-2055.

116. Kiyici M, Gurel S, Budak F, Dolar E, Gulten M, et al. (2003) Fas antigen (CD95) expression and apoptosis in hepatocytes of patients with chronic vira hepatitis. Eur J Gastroenterol Hepatol 15: 1079-1084.

117. Taieb J, Mathurin P, Poynard T, Gougerot-Pocidalo MA, Chollet-Martin S (1998) Raised plasma soluble fas and fas-ligand in alcoholic liver disease. Lancet 351: 1930-1931.

118. Hsu H, Xiong J, Goeddel DV (1995) The TNF receptor 1-associated protein TRADD signals cell death and NF-kappa B activation. Cell 81: 495-504.

119. Eum HA, Vallabhaneni R, Wang Y, Loughran PA, Stolz DB, et al. (2011) Characterization of DISC formation and TNFR1 translocation to mitochondria in TNF-alpha-treated hepatocytes. Am J Pathol 179: 1221-1229.

120. Schoemaker M, Ros J, Homan M, Trautwein C, Liston P, et al. (2002) Cytokine regulation of pro- and anti-apoptotic genes in rat hepatocytes: NF-kappaB- 
Citation: Karimian G, Faber KN, Moshage H (2013) Hepatocyte Apoptosis at the Interplay of Intracellular Organelles and Membrane-Bound Receptors: Targets for Therapy. Clin Exp Pharmacol S3:002. doi:10.4172/2161-1459.S3-002

Page 9 of 10

regulated inhibitor of apoptosis protein 2 (cIAP2) prevents apoptosis. J Hepatol 36: 742-50.

121. Micheau O, Tschopp J (2003) Induction of TNF receptor I-mediated apoptosis via two sequential signaling complexes. Cell 114: 181-190.

122. Okamoto H, Kimura M, Watanabe N, Ogihara M (2009) Tumor necrosis factor (TNF) receptor-2-mediated DNA synthesis and proliferation in primary cultures of adult rat hepatocytes: The involvement of endogenous transforming growth factor-alpha. Eur J Pharmacol 604: 12-19.

123. Kafrouni MI, Brown GR, Thiele DL (2003) The role of TNF-TNFR2 interactions in generation of CTL responses and clearance of hepatic adenovirus infection. $\mathrm{J}$ Leukoc Biol 74: 564-571.

124. Costelli P, Aoki P, Zingaro B, Carbo N, Reffo P, et al. (2003) Mice lacking TNFalpha receptors 1 and 2 are resistant to death and fulminant liver injury induced by agonistic anti-fas antibody. Cell Death Differ 10: 997-1004.

125. Malhi H (2007) TRAILs and tribulation. Hepatology 46: 1320-1322.

126. Walczak H, Miller RE, Ariail K, Gliniak B, Griffith TS, et al. (1999) Tumoricidal activity of tumor necrosis factor-related apoptosis-inducing ligand in vivo. Nat Med 5: 157-163

127. Ashkenazi A, Pai RC, Fong S, Leung S, Lawrence DA, et al. (1999) Safety and antitumor activity of recombinant soluble Apo2 ligand. J Clin Invest 104 155-162.

128. Volkmann X, Fischer U, Bahr MJ, Ott M, Lehner F, et al. (2007) Increased hepatotoxicity of tumor necrosis factor-related apoptosis-inducing ligand in diseased human liver. Hepatology 46: 1498-1508.

129. Herr I, Schemmer P, Buchler MW (2007) On the TRAIL to therapeutic intervention in liver disease. Hepatology 46: 266-274.

130. Mundt B, Kuhnel F, Zender L, Paul Y, Tillmann H, et al. (2003) Involvement of TRAIL and its receptors in viral hepatitis. FASEB J 17: 94-96.

131. Han LH, Sun WS, Ma CH, Zhang LN, Liu SX, et al. (2002) Detection of soluble TRAIL in HBV infected patients and its clinical implications. World $\mathrm{J}$ Gastroenterol 8: 1077-1080.

132. Babu CK, Suwansrinon K, Bren GD, Badley AD, Rizza SA (2009) HIV induces TRAIL sensitivity in hepatocytes. PloS One 4: e4623.

133. Farrell GC, Larter CZ, Hou JY, Zhang RH, Yeh MM, et al. (2009) Apoptosis in experimental NASH is associated with p53 activation and TRAIL receptor expression. J Gastroenterol Hepatol 24: 443-452.

134. Cazanave SC, Mott JL, Bronk SF, Werneburg NW, Fingas CD, et al. (2011) Death receptor 5 signaling promotes hepatocyte lipoapoptosis. J Biol Chem.

135. Kahraman A, Barreyro FJ, Bronk SF, Werneburg NW, Mott JL, et al. (2008) TRAIL mediates liver injury by the innate immune system in the bile ductligated mouse. Hepatology 47: 1317-1330.

136. Higuchi H, Grambihler A, Canbay A, Bronk SF, Gores GJ (2004) Bile acids upregulate death receptor 5/TRAIL-receptor 2 expression via a c-jun $\mathrm{N}$-terminal kinase-dependent pathway involving Sp1. J Biol Chem 279: 51-60.

137. Herbst RS (2004) Review of epidermal growth factor receptor biology. Int $J$ Radiat Oncol Biol Phys 59: 21-26.

138. Reinehr R, Haussinger D (2009) Epidermal growth factor receptor signaling in liver cell proliferation and apoptosis. Biol Chem 390: 1033-1037.

139. Michalopoulos GK (2007) Liver regeneration. J Cell Physiol 213: 286-300.

140. Jo M, Stolz DB, Esplen JE, Dorko K, Michalopoulos GK, et al. (2000) Crosstalk between epidermal growth factor receptor and c-met signal pathways in transformed cells. J Biol Chem 275: 8806-8811.

141. Fratto ME, Santini D, Vincenzi B, Silvestris N, Azzariti A, et al. (2011) Targeting EGFR in bilio-pancreatic and liver carcinoma. Frontiers in Bioscience 3: 16-22.

142. Svegliati-Baroni G, Ridolfi F, Hannivoort R, Saccomanno S, Homan M, et al. (2005) Bile acids induce hepatic stellate cell proliferation via activation of the epidermal growth factor receptor. Gastroenterology 128: 1042-1055.

143. Reinehr R, Graf D, Haussinger D (2003) Bile salt-induced hepatocyte apoptosis involves epidermal growth factor receptor-dependent CD95 tyrosine phosphorylation. Gastroenterology 125: 839-853.

144.Reinehr R, Schliess F, Haussinger D (2003) Hyperosmolarity and CD95L trigger CD95/EGF receptor association and tyrosine phosphorylation of CD95 as prerequisites for CD95 membrane trafficking and DISC formation. FASEB J 17: 731-733.

145. Reinehr R, Becker S, Eberle A, Grether-Beck S, Häussinger D (2005) Involvement of NADPH oxidase isoforms and src family kinases in CD95dependent hepatocyte apoptosis. J Biol Chem 280: 27179-94.

146. Reinehr R, Becker S, Keitel V, Eberle A, Grether-Beck S, et al. (2005) Bile salt-induced apoptosis involves $\mathrm{NADPH}$ oxidase isoform activation. Gastroenterology 129: 2009-2031.

147. Reinehr R, Becker S, Braun J, Eberle A, Grether-Beck S, et al. (2006) Endosomal acidification and activation of NADPH oxidase isoforms are upstream events in hyperosmolarity-induced hepatocyte apoptosis. J Bio Chem 281: 23150-23166.

148. Eberle A, Reinehr R, Becker S, Keitel V, Haussinger D (2007) CD95 tyrosine phosphorylation is required for CD95 oligomerization. Apoptosis 12: 719-729.

149. Lupberger J, Zeisel MB, Xiao F, Thumann C, Fofana I, et al. (2011) EGFR and EphA2 are host factors for hepatitis $C$ virus entry and possible targets for antiviral therapy. Nat Med 17: 589-595.

150. Vassilatis DK, Hohmann JG, Zeng H, Li F, Ranchalis JE, et al. (2003) The G protein-coupled receptor repertoires of human and mouse. Proceedings of the National Academy of Sciences of the United States of America 100: 49034908.

151. Milligan G, Kostenis E. (2006) Heterotrimeric G-proteins: A short history. Br J Pharmacol 1: S46-S55.

152. Laburthe M, Voisin T, El Firar A (2010) Orexins/hypocretins and orexin receptors in apoptosis: A mini-review. Acta Physiologica 198: 393-402.

153. Houben AJ, Moolenaar WH (2011) Autotaxin and LPA receptor signaling in cancer. Cancer Metastasis Rev.

154.Watters RJ, Wang HG, Sung SS, Loughran TP, Liu X (2011) Targeting sphingosine-1-phosphate receptors in cancer. Anti-Cancer Agents Med Chem.

155. Wagener BM, Marjon NA, Revankar CM, Prossnitz ER (2009) Adapto protein-2 interaction with arrestin regulates GPCR recycling and apoptosis. Traffic 10: 1286-1300.

156. Revankar CM, Vines CM, Cimino DF, Prossnitz ER (2004) Arrestins block G protein-coupled receptor-mediated apoptosis. J Biol Chem279: 24578-24584.

157. Lappano R, Maggiolini M (2011) G protein-coupled receptors: Novel targets for drug discovery in cancer. Nature Reviews. Drug Discovery 10: 47-60.

158. Murph MM, Hurst-Kennedy J, Newton V, Brindley DN, Radhakrishna H (2007) Lysophosphatidic acid decreases the nuclear localization and cellular abundance of the p53 tumor suppressor in A549 lung carcinoma cells. Mo Cancer Res : MCR 5: 1201-1211.

159. Fraser CC (2008) G protein-coupled receptor connectivity to NF-kappaB in inflammation and cancer. Int Rev Immunol 27: 320-350.

160. Fishman P, Bar-Yehuda S, Ohana G, Barer F, Ochaion A, et al. (2004) An agonist to the $\mathrm{A} 3$ adenosine receptor inhibits colon carcinoma growth in mice via modulation of GSK-3 beta and NF-kappa B. Oncogene 23: 2465-2471.

161. McAllister-Lucas L, Ruland J, Siu K, Jin X, Gu S, et al. (2007) CARMA3/Bcl10 MALT1-dependent NF-kappaB activation mediates angiotensin II-responsive inflammatory signaling in nonimmune cells. Proc Natl Acad Sci U S A 104: 139-44.

162. Brasier A, Jamaluddin M, Han Y, Patterson C, Runge M (2000) Angiotensin II induces gene transcription through cell-type-dependent effects on the nuclear factor-kappaB (NF-kappaB) transcription factor. Mol Cell Biochem 212: 155 69.

163. Davaille J, Li L, Mallat A, Lotersztajn S (2002) Sphingosine 1-phosphate triggers both apoptotic and survival signals for human hepatic myofibroblasts. J Biol Chem 277: 37323-37330.

164. Han MS, Park SY, Shinzawa K, Kim S, Chung KW, et al. (2008) Lysophosphatidylcholine as a death effector in the lipoapoptosis of hepatocytes. J Lipid Res 49: 84-97.

165. Maiga A, Mourier G, Quinton L, Rouget C, Gales C, et al. (2011) G proteincoupled receptors, an unexploited animal toxin targets: Exploration of green mamba venom for novel drug candidates active against adrenoceptors. Toxicon. 
Citation: Karimian G, Faber KN, Moshage H (2013) Hepatocyte Apoptosis at the Interplay of Intracellular Organelles and Membrane-Bound Receptors: Targets for Therapy. Clin Exp Pharmacol S3:002. doi:10.4172/2161-1459.S3-002

166. Kimple AJ, Bosch DE, Giguere PM, Siderovski DP (2011) Regulators of G-protein signaling and their $\mathrm{G}\{$ alpha\} substrates: Promises and challenges in their use as drug discovery targets. Pharmacol Rev 63: 728-749.

167. Gonzalez-Maeso J (2011) GPCR oligomers in pharmacology and signaling. Mol Brain 4: 20
168. Karimian G, Buist-Homan M, Faber KN, Moshage H (2012) Pertussis toxin, an inhibitor of G(alphai) PCR, inhibits bile acid- and cytokine-induced apoptosis in primary rat hepatocytes. PloS One 7: e43156.

169. Muntane $\mathrm{J}$ (2011) Targeting cell death and survival receptors in hepatocellular carcinoma. Anti-Cancer Agents in Med Chem 11: 576-584
This article was originally published in a special issue, Signaling Pathways in Functional Cells handled by Editor(s). Dr. Li-Na Wei, University of Minnesota, USA 